\title{
Effect of limestone powder on strength and permeability of cementitious mortars
}

\author{
Wei-Ting Lin ${ }^{1, *}$, An Cheng ${ }^{1}$, and Robert Černý ${ }^{2}$ \\ ${ }^{1}$ National Ilan University,,Department of Civil Engineering, Shennong Rd., I-Lan 260, Taiwan \\ ${ }^{2}$ Czech Technical University in Prague, Faculty of Civil Engineering, Department of Materials \\ Engineering and Chemistry, Thákurova 7, 16629 Prague 6, Czech Republic
}

\begin{abstract}
This study investigated the mechanical properties and durability of mortar specimens containing various quantities of waste limestone powder $(0 \%, 10 \%, 20 \%$, and $30 \%$ of the weight of cement). The mechanical properties were evaluated in terms of flowability, compressive strength, and splitting tensile strength. Permeability was evaluated in terms of resistivity, absorption, and rapid chloride penetration (total chargepassed). Test results revealed that replacing $10 \%$ of the cement with limestone powder improves both mechanical performance and durability. However, reducing the cement content reduced the availability of hydration products to fill the pores in the microstructure. The hydration product of limestone powder was mainly calcium hydroxide, which undermines the development of strength in the paste. Nonetheless, our results indicate that waste limestone powder is suitable for the partial replacement of cement.
\end{abstract}

\section{Introduction}

The processing of stone by cutting, carving, and grinding produces stone waste in the form of sludge with a composition similar to that of the original stone $[1,2]$. This waste material has a potentially considerable economic value [3, 4]. The stone-processing industry in Taiwan is centred in the city of Hualien, where it generates an annual economic output of nearly 40 billion yuan. Despite this enormous output, the efficiency of resource utilisation is somewhat limited $[5,6]$.

It seems worth investigating whether stone sludge could serve as a raw material in cement products, lightweight building materials, and fibreboard. At present, most stone waste goes into the fabrication of permeable bricks and bituminous mixtures [11-13]. Note that the use of limestone powder in cementitious materials, such as fly ash and granulated blast furnace slag, is being phased out in Taiwan. New uses must be found for this valuable resource. In this study, we examined the feasibility of using waste limestone powder as a replacement for cement in concrete.

\footnotetext{
*Corresponding author: wtlin@ @iu.edu.tw
} 


\section{Materials and test procedures}

The chemical composition of the waste limestone powder used in this study (An Jung Mineral Chemical Corporation) is summarised in Table 1. The white-grey limestone powder had a specific gravity of 2.70 and the main constituent was calcium oxide.

Table 1. Chemical composition of waste limestone powder.

\begin{tabular}{|c|c|c|c|c|c|c|c|}
\hline Item & Cinc./\% & Sigma/\% & RSD/\% & LLD/\% & Net area & Backgr. & Chi \\
\hline $\mathrm{Ca}$ & 99.43 & 0.100 & 0.1 & 0.02 & 917,292 & 2,961 & 5.16 \\
\hline $\mathrm{Mn}$ & 0.099 & 0.003 & 2.5 & 0.003 & 2,796 & 1,051 & 1.39 \\
\hline $\mathrm{Fe}$ & 0.345 & 0.003 & 1.0 & 0.003 & 12,401 & 1,053 & 0.81 \\
\hline $\mathrm{Sr}$ & 0.129 & 0.001 & 1.0 & 0.002 & 15,182 & 4,752 & 1.16 \\
\hline
\end{tabular}

In accordance with ASTM C150 standards, the cement used in this study was type I Portland cement with a specific gravity of 3.15. The properties of the fine aggregate were specific gravity (2.65), water absorption (1.93\%), and fineness modulus (2.25). The mix designs used for the mortar specimens are listed in Table 2. Limestone powder was used as a partial replacement for cement $(0 \%, 10 \%, 20 \%$, and 30\%) with a water/binder ratio (W/B) of 0.40 and flowability controlled at $115 \%$.

Table 2. Mix designs of mortar specimens $\left(\mathrm{kg} / \mathrm{m}^{3}\right)$.

\begin{tabular}{|c|c|c|c|c|c|}
\hline Mix no. & W/B & Water & Cement & Limestone powders & Fine aggregates \\
\hline OPC & & 210 & 525.0 & 0 & 1,684 \\
\cline { 1 - 4 } LP10 & \multirow{3}{*}{0.40} & 210 & 472.5 & 52.5 & 1,684 \\
\cline { 3 - 6 } & & 210 & 420.0 & 105.0 & 1,684 \\
\hline LP20 & & 210 & 367.5 & 157.5 & 1,684 \\
\hline LP30 & & & & & \\
\hline
\end{tabular}

OPC denotes ordinary Portland cement and LP refers to limestone with a number to indicate the percentage replacement. Table 3 lists test methods, dimensions of the test specimens, and testing standards.

Table 3. Test parameters.

\begin{tabular}{|c|c|c|c|}
\hline Test methods & $\begin{array}{c}\text { Specimen dimensions } \\
(\mathbf{m m})\end{array}$ & Standard & $\begin{array}{c}\text { Testing } \\
\text { period (days) }\end{array}$ \\
\hline $\begin{array}{c}\text { Compressive strength } \\
\text { test }\end{array}$ & $50 \times 50 \times 50$ & ASTM C109 & $3,7,28,56$ \\
\hline $\begin{array}{c}\text { Splitting tensile } \\
\text { strength test }\end{array}$ & $\phi 100 \times 200$ & ASTM C496 & $3,7,28,56$ \\
\hline Resistivity test & $\phi 100 \times 200$ & $\begin{array}{c}\text { ASTM } \\
\text { WK37880 }\end{array}$ & $3,7,28,56$ \\
\hline Water absorption test & $\phi 100 \times 200$ & ASTM C642 & $3,7,28,56$ \\
\hline $\begin{array}{c}\text { Rapid chloride } \\
\text { penetration test }\end{array}$ & $\phi 100 \times 50$ & ASTM C1202 & 56 \\
\hline
\end{tabular}




\section{Results and discussion}

The results of compressive strength for all mixes are shown in Fig. 1. The addition of limestone powder was shown to increase the strength of all samples, regardless of the curing duration. At 3 and 7 days, the LP10 specimens presented the highest strength (34.21 $\mathrm{MPa}$ ) followed by LP20 (31.55 MPa). At 28 and 56 days, the compressive strength of the experiment specimens still exceeded that of the control specimens: LP10 (+51\%) and LP20 $(+42.62 \%)$. It seems that the inclusion of limestone powder in cement-based composites can increase compressive strength; however, the magnitude of the improvements drops at replacement values exceeding $10 \%$.

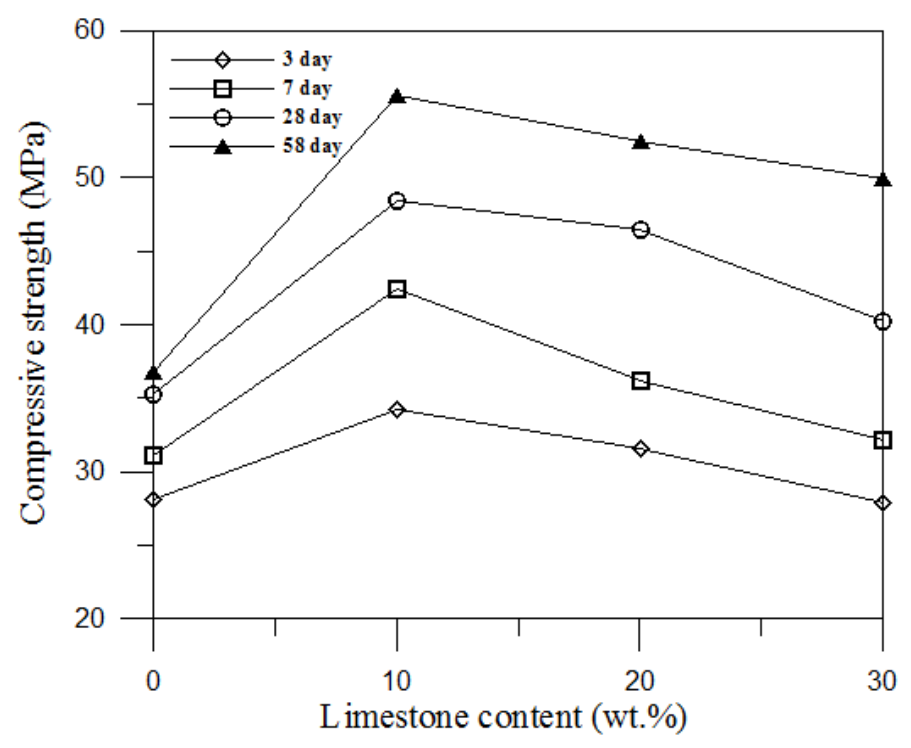

Fig. 1. Compressive strength development curves versus limestone content.

The results of splitting tensile strength are illustrated in Fig. 2. At 3 days, the addition of limestone powder was shown to increase the splitting tensile strength, compared to OPC specimens. At 28 days, the splitting strength of the samples was as follows: OPC (4.30 MPa), LP10 (4.32 MPa), LP20 (4.21 MPa), and LP30 (4.12 MPa). At 56 days, the splitting strength of the LP specimens still exceeded that of the OPC specimen; however, the magnitude of the improvements dropped at replacement values exceeding $10 \%$. The gradual decrease in the amount of cement may result in a lack of aluminate (such as $\mathrm{C}_{3} \mathrm{~A}$ ) and hydrated limestone powder [4]. 


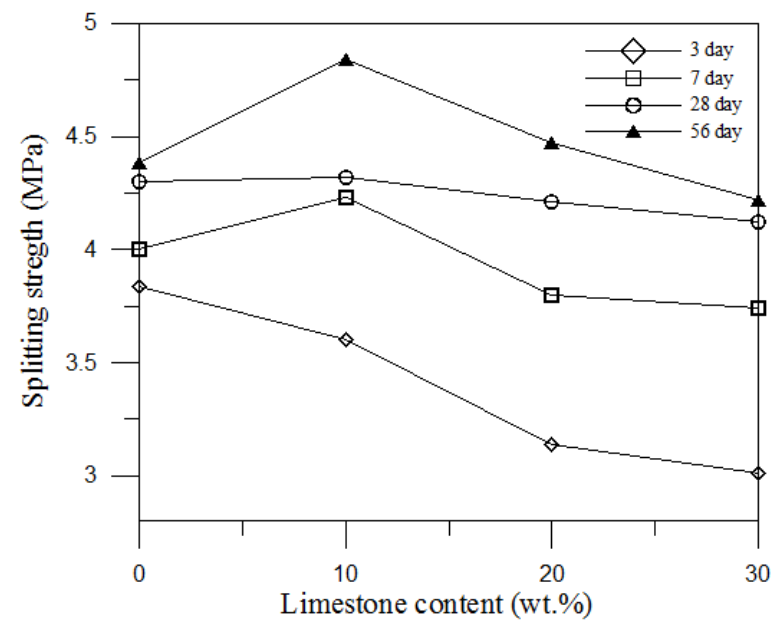

Fig. 2. Splitting tensile strength development curves versus limestone content.

The Wenner four-electrode resistance index is used to evaluate the quality of cementbased materials in terms of permeability. Essentially, this index measures the resistivity of specimens saturated with water as an indication of microstructure development, wherein higher resistivity values indicate a denser internal microstructure.

The resistivity results are illustrated in Fig. 3. The resistivity of the LP specimens was significantly lower than that of the control specimens (i.e., OPC). Furthermore, the timedependent increase in microstructure density was more pronounced in the OPC specimens, as indicated by a growing discrepancy in the resistivity values of specimens with or without limestone powder. At 56 days, the resistivity of the LP30 specimen was $43 \%$ below that of the OPC specimens. Clearly, the addition of limestone powder hindered the formation of the internal microstructure. This can presumably be attributed to reactions between the hydration products of limestone and cement resulting in greater porosity and a looser microstructure.

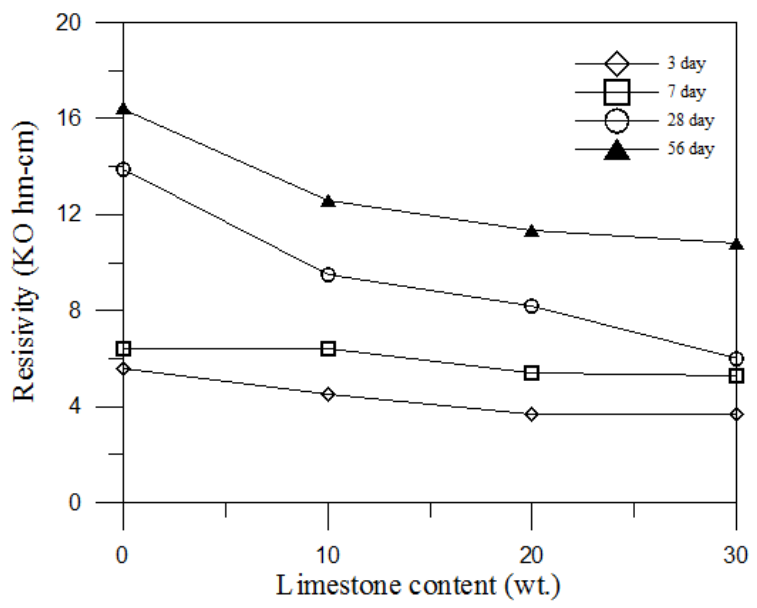

Fig. 3. Resistivity development curves versus limestone content.

Saturated water absorption tests are used as an index of permeability indicating the overall quality of cement-based materials, wherein water absorption is proportional to the number of pores. Materials with fewer pores possess a denser internal microstructure 
capable of resisting the penetration of harmful substances which might otherwise damage the material over time.

The results of water absorption tests are illustrated in Fig. 4. At 3 and 7 days, LP samples absorbed less water than the control specimens did. This can be attributed to limestone powder reacting more quickly than the cement in the formation of hydration products to fill in pores. Over time, the benefits of the limestone powder in terms of reducing porosity diminished. In later stages, only the LP10 sample outperformed the OPC in terms of water absorption: 28 days $(+3 \%)$ and 56 days $(+2 \%)$. Clearly, adding more than $10 \%$ limestone powder would be of no benefit in reducing the porosity of composites.

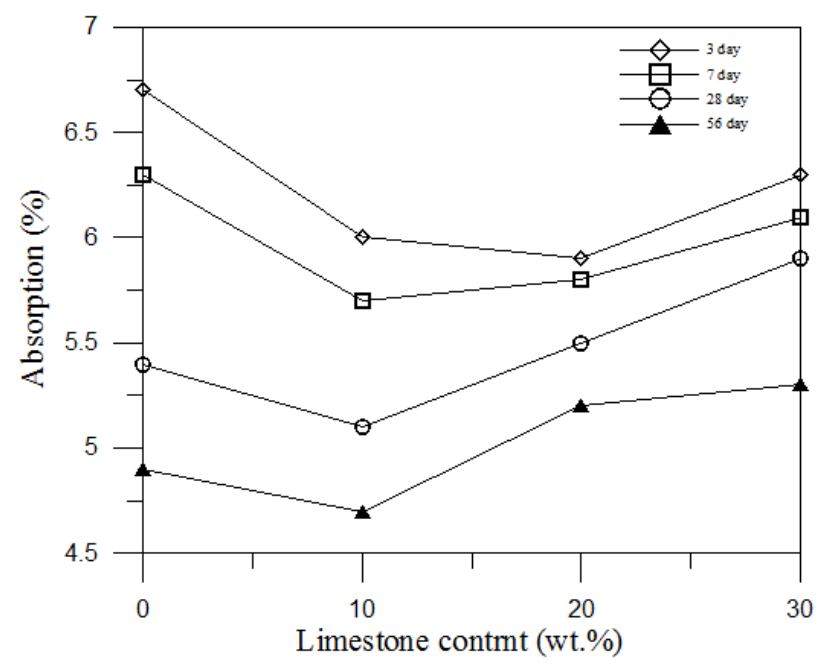

Fig. 4. Water absorption development curves versus limestone content.

The rapid chloride penetration test (RCPT) measures the resistance of composite specimens to chloride ion penetration as an indicator of durability. Table 4 lists the total charge-passed (cumulative coulombs) and total current at 56 days. Under a test duration of 6 hours, the LP10 specimens presented the lowest total charge-passed (2,272 coulombs), followed by LP20 (5,216 coulombs), and LP30 (5,623 coulombs). It appears that the inclusion of more than $10 \%$ limestone powder increased the number of fine pores during hydration with a corresponding increase in chloride ion penetration.

Table 4. RCPT test results.

\begin{tabular}{|c|c|c|c|}
\hline \multirow{2}{*}{ Mix no. } & \multicolumn{3}{|c|}{ Measured current (mA) } \\
\cline { 2 - 4 } & LP10 & LP20 & LP30 \\
\hline $30-60-90$ & 0 & 0 & 0 \\
\hline $120-150-180$ & 0 & 0 & 12 \\
\hline $210-240-270$ & 64 & 884 & 1,884 \\
\hline $300-330-360$ & 1,544 & 2,600 & 1,228 \\
\hline $\begin{array}{c}\text { total charge-passed } \\
\text { (cumulative coulombs) }\end{array}$ & 2,272 & 5,216 & 5,623 \\
\hline
\end{tabular}




\section{Conclusions}

Our conclusions are as follows:

1. The LP10 specimens presented the highest compressive strength and splitting tensile strength, closely followed by LP20.

2. The inclusion of limestone powder as a replacement for cement had a negative effect on permeability and durability in a dose-dependent manner. In rapid chloride penetration tests, the total charge passed through LP30 specimens was 2.47 times higher than that of LP10. These results are consistent with those pertaining to resistivity and absorption.

3. Replacing more than $10 \%$ of the cement with limestone powder was shown to hinder the formation of hydration products required to fill the capillary pores and gel pores, resulting in a microstructure of lower density.

4. In terms of mechanical properties and permeability, it appears that up to $10 \%$ of the cement could be replaced with limestone powder without adverse effects.

Acknowledgements: This work has been financed by Polish National Agency for Academic Exchange under the International Academic Partnership Programme within the framework of the grant: Emobility and sustainable materials and technologies EMMAT. This work also has been supported by the Ministry of Science and Technology (MOST-108-2221-E-197-006) in Taiwan and the Grant Agency of the Czech Technical University in Prague, Project No. SGS19/143/OHK1/3T/11.

\section{References}

1. R. Zulcão, J. L. Calmon, T. A. Rebello, D. R. Vieira, Constr. Build. Mater. 257, 119523 (2020)

2. W. A. Moura, J. P. Gonçalves, R. S. Leite, Sitientibus 26, 49 (2002)

3. M. C. Juenger, R. Snellings, S. A. Bernal, Cem. Concr. Res. 122, 257 (2019)

4. D. K. Panesar, R. Zhang, Constr. Build. Mater. 251, 118866 (2020)

5. L. D. Ellis, A.F. Badel, M. L. Chiang, R. J. Y. Park, Y. M. Chiang, Proc. Natl. Acad. Sci. 117, 12584 (2020)

6. Q. D. Nguyena, A. Castel, Cem. Concr. Res. 132, 106051 (2020)

7. R. D. Hooton, Cem. Concr. Res. 78, 165 (2015)

8. I. G. Richardson, Cem. Concr. Res. 38, 137 (2008)

9. R. S. Macedo, C. Ulsen, A. Mueller, Constr. Build. Mater. 229, 116875 (2019)

10. S. Palm, T. Proske, M. Rezvani, S. Hainer, C. Müller, C. A. Graubner, Constr. Build. Mater. 119, 308 (2016)

11. M. Ghrici, S. Kenai, M. Said-Mansour, Cement Concr. Compos. 29, 542 (2007)

12. Á. Fernández, J. G. Calvo, M. C. Alonso, Cement Concr. Compos. 89, 238 (2018)

13. D. Vaičiukynienè, I. Pundienè, A. Kantautas, A. Augonis, E. Janavičius, V. Vaičiukynas, J. Alobeid, J. Clean. Prod. 244, 118493 (2020) 